\title{
Green Nanoparticles - A Novel Approach for the Management of Banana Anthracnose Caused by Colletotrichum musae
}

\author{
Divya Jagana*, Yashoda R. Hegde and Rajasekhar Lella \\ Department of Plant Pathology, College of Agriculture, University of Agricultural Sciences, \\ Dharwad- 580005, Karnataka, India \\ *Corresponding author
}

\section{A B S T R A C T}

\begin{tabular}{|l|}
\hline Key w or d s \\
Green nanoparticles, \\
Neem, Banana \\
anthracnose, \\
Colletotrichum musae, \\
Disease management, \\
*PDI: Per cent disease \\
index.
\end{tabular}

\begin{abstract}
Anthracnose of banana is caused by Colletotrichum musae and is one of the most serious diseases of ripe banana. Plant-mediated biological synthesis of nanoparticles is gaining importance in recent years due to its simplicity and eco-friendliness in the management of plant diseases. Present investigation was carried out during 2015-16 in department of plant pathology, UAS, Dharwad on management of banana anthracnose by using green nanoparticles. Efficacy of green nanoparticles (ajwain and neem leaf extract) of copper, silver, nickel and magnesium has been studied in vitro at different concentrations against C. musae. Silver-Neem nano particles (Ag-Neem Nps) were tested in vivo for their bioefficacy against anthracnose as postharvest spraying at $0.01,0.02,0.05,0.1$ and 0.2 per cent concentrations. In vitro studies revealed that Ajwain-Mg NPs, Ajwain-Ni NPs at 0.2 per cent and Neem-Ag NPs at 0.1 and 0.2 per cent have shown complete inhibition of spore germination of C. musae. Spraying of Ag-Neem np at 0.2 per cent concentration recorded lowest disease severity (6.67 PDI)* which was on par with 0.1 and 0.05 per cent concentrations (8.89 PDI) and.
\end{abstract}

\section{Introduction}

Banana is one of the most popular fruits in India and many tropical countries and important dessert fruit in India. Major economic part of the banana plant is the fruit, suffers from many postharvest diseases. Anthracnose of banana is caused by Colletotrichum musae and is one of the most serious diseases of ripe banana. Symptoms of anthracnose include black and sunken lesions with spore masses or acervuli in the lesion. This has been a major constraint in the marketing of fruit intended for local as well as distant markets. Control of postharvest diseases has been traditionally achieved by pre and postharvest applications of fungicides. However, at present situation producers have been compelled to seek alternative methods due to increased global demand for chemical-free fresh produce (Korsten, 2006) and due to issues like development of resistance in plant pathogens against currently used fungicides. Plant pathologists made a late start in harnessing the benefits of nanomaterials for management of plant pathogens. There have been some exciting results obtained especially in plant disease management aspects concerning fungi, bacteria and flowering plant parasite by developing nanoparticles of different metals, pesticides and growth promoters (Banik and 
Sharma, 2011). Biogenic silver nanoparticles (Ag NPs) are proved to be potential antimicrobial agents against an array of pathogens [Elumalai and Vinothkumar, 2013]. In present study, Green nanoparticles of silver, copper, nickel and magnesium were evaluated at different concentrations for inhibition of mycelial growth and spore germination of $C$. musae. Postharvest spraying on fruits with Neem-Ag nanoparticles was also investigated for efficient disease management.

\section{Materials and Methods}

\section{In vitro evaluation of green nanoparticles}

\section{Agar well diffusion method}

Present investigation was carried out during 2015-16 in department of plant pathology, University of Agricultural Sciences, Dharwad on management of banana anthracnose by using green nanoparticles. Green nanoparticles $(68 \mathrm{~nm})$ of different metals (copper, silver, nickel and magnesium) synthesized from ajwain and neem leaf extracts were screened for antifungal activity at different concentrations by agar well diffusion method according to Bobbaralal et al., (2009) Procedure with modifications. The synthesized green nano particles were obtained from nanotechnology laboratory, University of agriculture sciences, Dharwad. Seven day old cultures grown on potato dextrose agar (PDA) were used for inoculation of fungal strain on PDA plates. An aliquot $(100 \mu \mathrm{l})$ of inoculums was introduced to molten PDA and poured in to a Petri dish by pour plate technique. After solidification, the appropriate wells were made on agar plate by using cork borer. In agar wells created, $30 \mu \mathrm{l}$ nanoformulations of the test concentrations were loaded by using micropippet. Plates were incubated at $25 \pm 2{ }^{\circ} \mathrm{C}$ for 48-72 $\mathrm{hr}$ and inhibition zone around the wells in the plates. The antifungal activity was evaluated by measuring zones of inhibition of fungal growth surrounding the wells filled with nano particles. Sterile water and a standard fungicide served as checks, the experiment was carried out in triplicates.

\section{Inhibition of spore germination}

Conidial suspension of $C$. musae was prepared in sterile water. Green nanoparticles from the stock were diluted in sterile water to get the required concentration; both spore suspension and green nanoparticles of different concentrations were mixed together in a cavity slide in equal proportions. Slides were incubated under room temperature for $24 \mathrm{hr}$ in moist chambers. The observations on number of spores germinated and total number of spores in each microscopic field was recorded under compound microscope. Sterile water/fungicide/plant extract served as control. Per cent inhibition of spore germination was calculated by formula given by Vincent (1947) and data was later analysed statistically.

\section{In vivo evaluation of green nano particles}

Fruits selected for in vivo studies were at mature green stage, free from blemishes and injuries. Banana fingers with intact crown portion were sterilized in 1.0 per cent sodium hypochlorite and rinsed with sterilized distilled water. Neem-silver nanoparticles were evaluated at different concentrations $(0.01,0.02,0.05,0.1$ and $0.2 \% \mathrm{v} / \mathrm{v})$ as postharvest spray on fruits. Spray of $\mathrm{AgNO}_{3}$ at 0.017 per cent, neem leaf extract at 20 per cent and sterilized water served as controls. Spore suspension of $C$. musae $\left(1 \times 10^{5}\right.$ spores $/ \mathrm{ml}$ ) was sprayed on the treated fruits and kept for incubation in moist chambers at room temperature. Observations were recorded on per cent area infected on fruit in 0-5 scale i.e. [0]- No symptoms on fruit 
surface, (1) $0.1-5 \%$ area covered by lesions, (2) $5.1-10 \%$ area covered by lesions, (3) $10.1-25 \%$ area covered by lesions, (4) 25.1 - $50 \%$ area covered by lesions and (5) $50 \%$ of area covered by lesions after eight days of inoculation. Per cent disease index was computed by using the formula given by Wheeler (1969) and analysed statistically. Per cent disease reduction in different treatments over control was derived by using the formula suggested by Vincent.

\section{Statistical analysis}

The experiment was laid out in a completely randomized design (CRD) with treatments in different concentrations in three replications. The experiment was conducted at room temperature in the laboratory. Statistical analysis was done as per the procedures given by Gomez and Gomez (1984). All comparisons of means were subjected to analysis of variance (ANOVA) and the significant differences among treatments were determined with a least significant difference (lsd) separation test. Arcsine or square root transformation was used wherever required to normalize variance.

\section{Results and Discussion}

\section{In vitro evaluation of green nanoparticles}

Green nanoparticles of silver, copper, nickel and magnesium were evaluated at different concentrations for inhibition of mycelial growth and spore germination of $C$. musae and results are shown in Table 1and Fig 1. Green nanoparticles of silver, copper, nickel and magnesium have not considerably inhibited the mycelial growth however; spore germination inhibition was appreciable in vitro condition. Most of the treatments could show significant inhibition of spore germination. Ajwain-Mg NPs, Ajwain-Ni NPs (@0.2\%) and Neem-Ag NPs (@ 0.1 \& $0.2 \%$ ) have shown complete inhibition which was statistically at par with Ajwain-Ni NPs (99.05\%) and Ajwain-Mg NPs (97.09\%) at 0.1 per cent concentration. Metal nanoparticles probably cause damage on spores due to high penetration activity. Supporting to the current findings, antifungal property of 'Chitosan-silver nanoparticlecomposite as reported by Lamsal et al., (2011) against mango anthracnose pathogen C. gloeosporioides (Chowdappa et al., 2014). Similar reports were made in another in vitro assay of silver nanoparticle (WA-PR-WB13R [PR]) against isolates of Colletotrichum sp. These results have also validated the report of Aguilar-Méndez and co-workers (2011) who suggested that silver nanoparticles can significantly reduce the mycelial growth of $C$. gloeosporioides under in vitro condition.

\section{In vivo evaluation of green nanoparticles}

Bioefficacy of silver neem-silver nanoparticles was investigated as postharvest spray on the fruits and results (Table $2 \&$ Fig $2)$ indicated that all the treatments $(0.2 \%$, $0.1 \%, 0.05 \%, 0.02 \%$ and $0.01 \%$ NeemAg-np) exhibited effective disease reduction over control, maximum disease reduction was found in fruits treated with 0.2 percent NeemAg-np (91.43\%) (6.67 PDI) which was on par with 0.1 and 0.05 per cent NeemAg-np in which 88.57 per cent disease reduction (8.89 PDI) was noticed. NeemAg-np was found to be effective even at lower concentrations $(0.02 \%$ and $0.01 \%)$ as well, showing 82.86 per cent disease reduction. Neem leaf extract $(20.0 \%$ concentration) could give only 37.14 per cent disease reduction. Meanwhile, $\mathrm{AgNO}_{3}$ showed 80 per cent disease reduction. Silver nanoparticles might have caused deformities in spores and the shape of hyphal walls. This is consistant with the findings of Lamsal and coworkers [2011] where in the efficacy of silver nanoparticles against pepper anthracnose $(C$. gloeosporioides) was well demonstrated at 50 ppm to prevent the disease outbreak. 
Table.1 In vitro evaluation of green nano particles against Colletotrichum musae

\begin{tabular}{|l|c|c|c||}
\hline \multicolumn{1}{|c|}{ Treatment } & $\begin{array}{c}\text { Concentration } \\
(\%)\end{array}$ & $\begin{array}{c}\text { Per cent inhibition of } \\
\text { mycelial growth }\end{array}$ & $\begin{array}{c}\text { Per cent inhibition of spore } \\
\text { germination }\end{array}$ \\
\hline \hline Ajwain-Ni NPs & 0.1 & $6.37(14.60) *$ & $99.05(86.76)^{*}$ \\
\hline Ajwain-Ni NPs & 0.2 & $8.46(16.91)$ & $100.00(90.00)$ \\
\hline Ajwain-Mg NPs & 0.1 & $2.47(9.04)$ & $97.09(82.06)$ \\
\hline Ajwain-Mg NPs & 0.2 & $4.35(12.03)$ & $100.00(90.00)$ \\
\hline Ajwain-K NPs & 0.1 & $8.09(16.52)$ & $77.76(61.95)$ \\
\hline Ajwain-K NPs & 0.2 & $4.64(12.43)$ & $81.29(64.43)$ \\
\hline Neem-Ag NPs & 0.05 & $2.32(8.75)$ & $90.98(72.60)$ \\
\hline Neem-Ag NPs & 0.1 & $2.32(8.76)$ & $100.00(90.00)$ \\
\hline Neem-Ag NPs & 0.2 & $4.87(12.73)$ & $100.00(90.00)$ \\
\hline $\begin{array}{l}\text { Propiconazole @ } \\
\text { 0.05\% }\end{array}$ & 0.1 & $100.00(90.00)$ & $100.00(90.00)$ \\
\hline S.Em \pm & & 0.35 & 1.31 \\
\hline CD at 1\% & 1.39 & 5.28 \\
\hline CV \% & \multicolumn{2}{|c|}{2.97} & 2.40 \\
\hline \hline
\end{tabular}

*Arcsine transformed values

Table.2 Bioefficacy of green nano for the management of banana anthracnose

\begin{tabular}{|l|c|}
\hline \multicolumn{1}{|c|}{ Treatment } & Per cent disease index \\
\hline \hline Neem Ag nanoparticles @ 0.2\% & $6.67(14.96)^{*}$ \\
\hline Neem Ag nanoparticles @ 0.1\% & $8.89(17.35)$ \\
\hline Neem Ag nanoparticles @ 0.05\% & $8.89(17.35)$ \\
\hline Neem Ag nanoparticles @ 0. 02\% & $13.33(21.42)$ \\
\hline Neem Ag nanoparticles @ 0.01\% & $13.33(21.42)$ \\
\hline AgNO 3 @ 0.017\% & $15.56(23.23)$ \\
\hline Neem leaf extract @ 20 \% & $48.89(44.36)$ \\
\hline Control & $75.56(61.88)$ \\
\hline S.Em \pm & 1.28 \\
\hline CD at 5\% & 3.88 \\
\hline
\end{tabular}

*Arcsine transformed values 

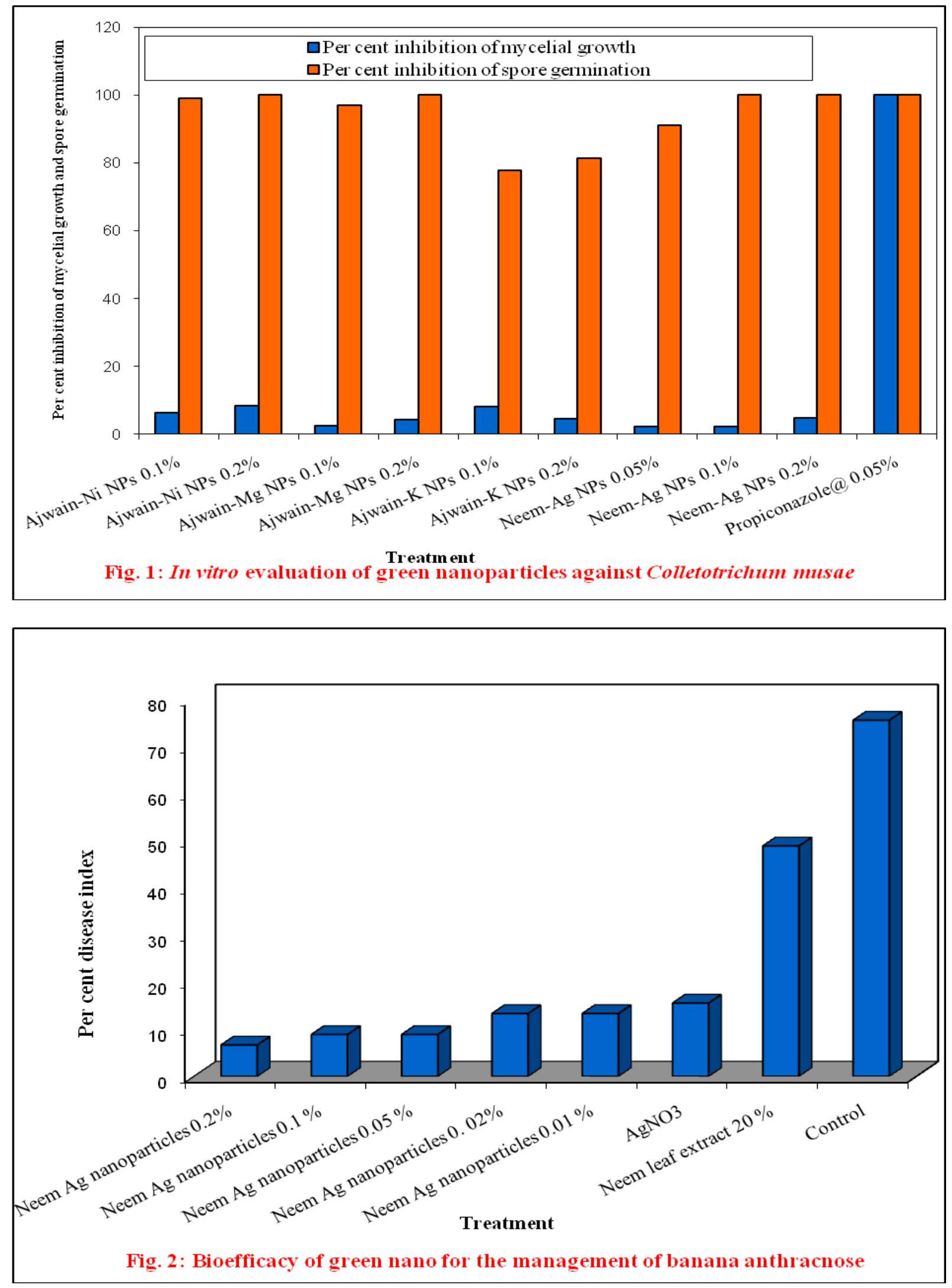


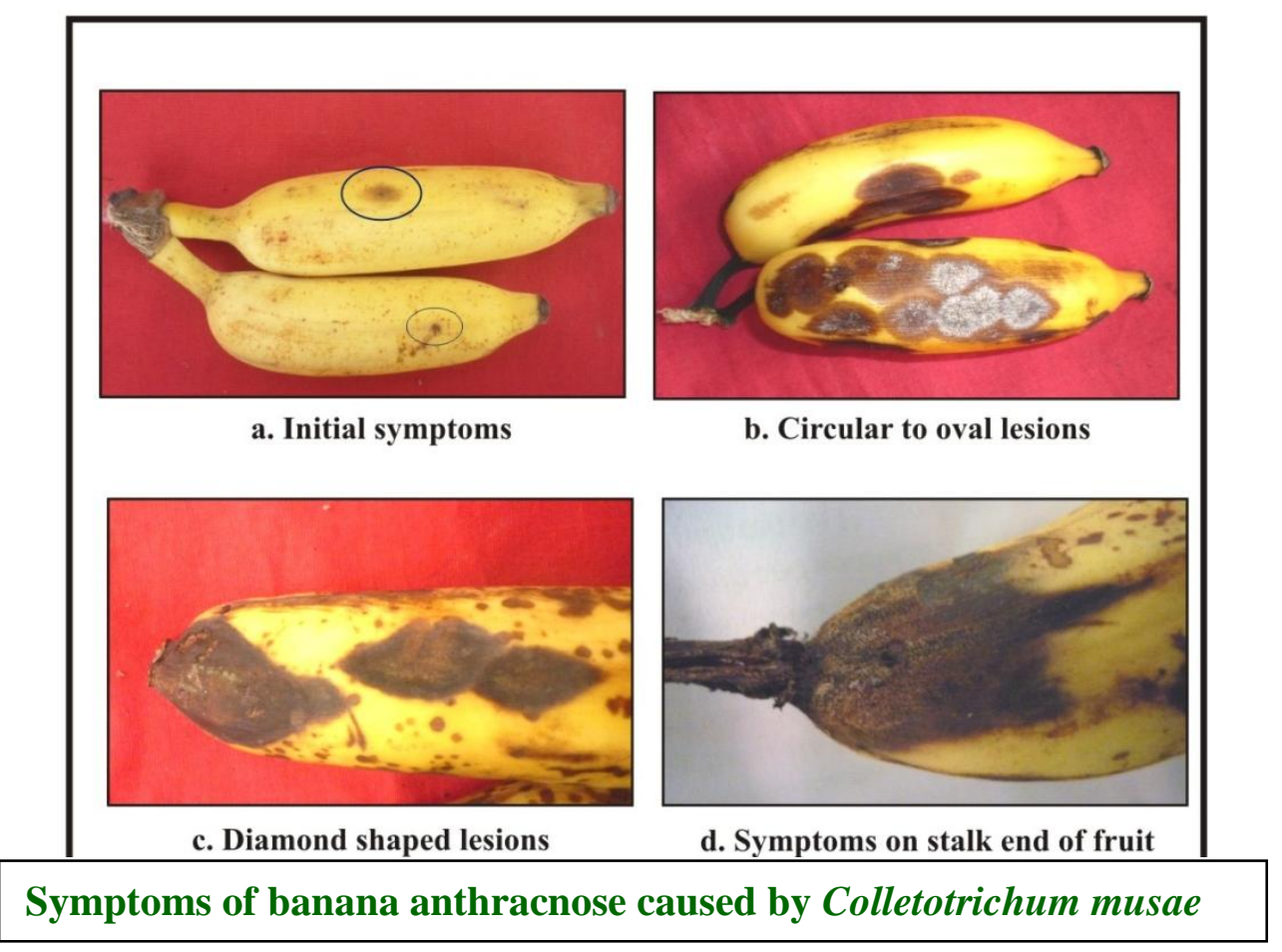

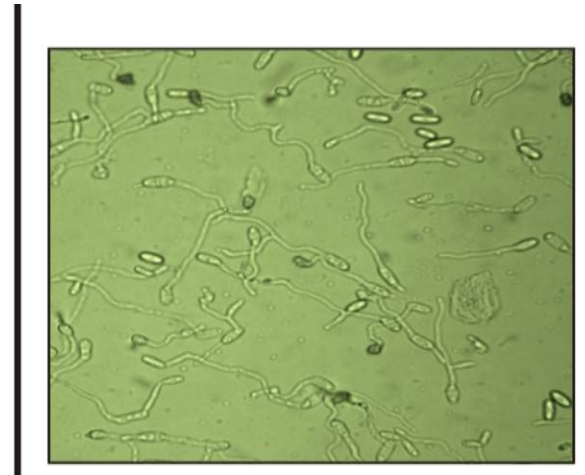

Control

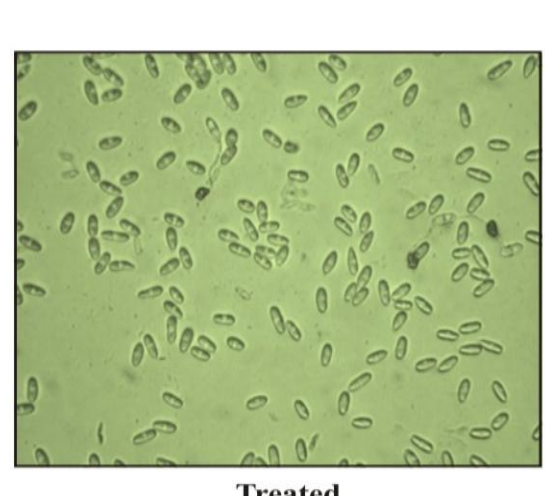

Treated

Plate 19: In vitro evaluation of green nano particles against $C$. musae

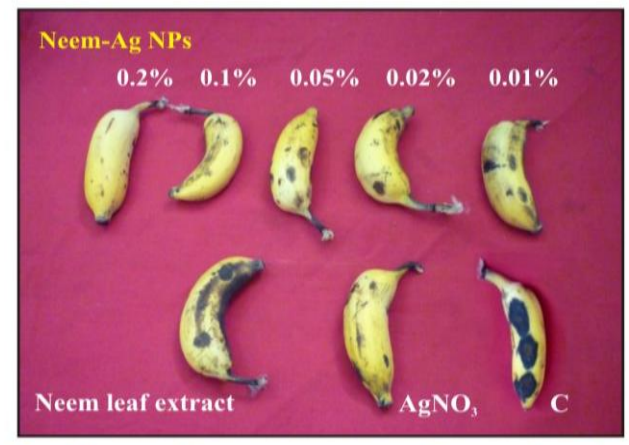

Plate 24: Bioefficacy of green nano particles against Anthracnose 


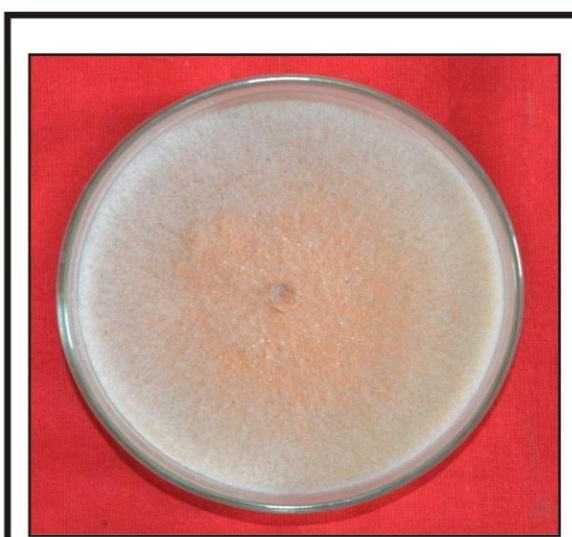

a. Eight days old culture

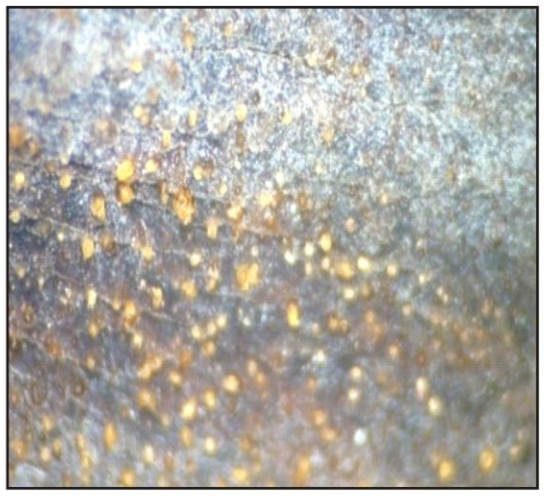

c. Acervuli on host surface

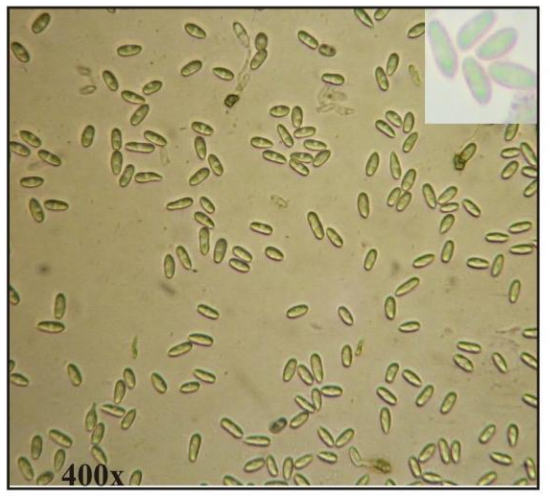

e. Conidia

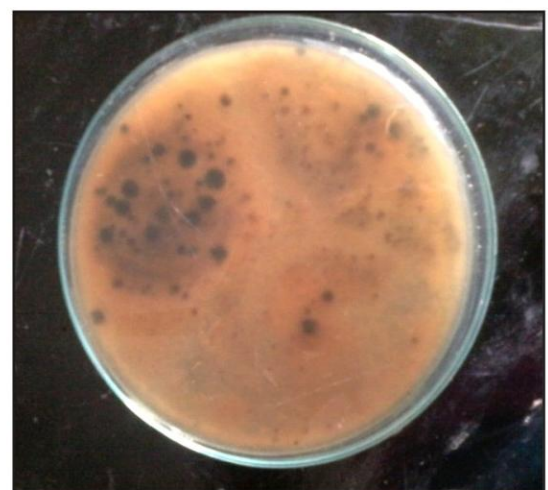

b. Acervuli in 20 days old culture

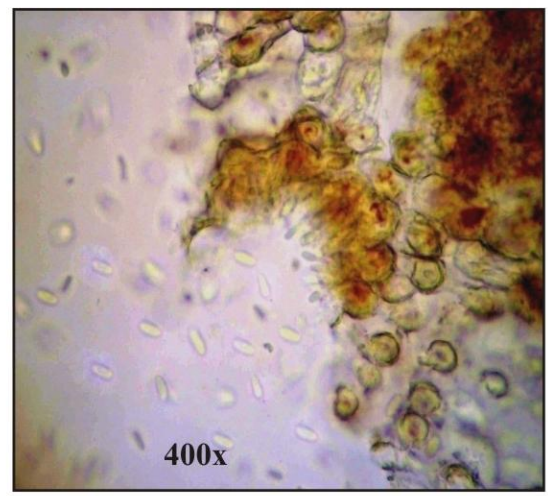

d. Acervulus

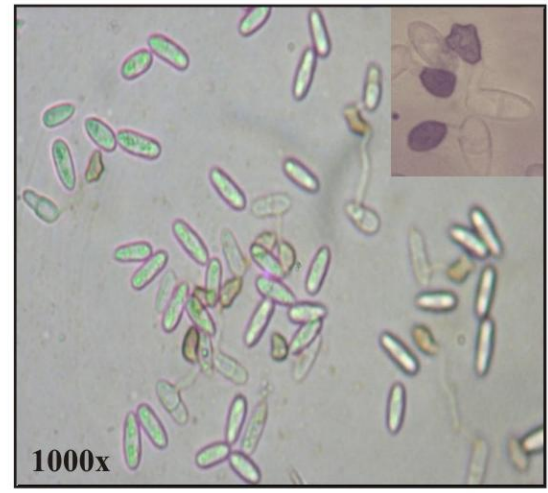

f. Appressorial formation

Plate 5: Cultural and morphological characteristics of Colletotrichum musae

Mode of action of nanaparticles was explained by different researchers. Samuel and Guggenbichler (2004) shown that the nanoparticles efficiently penetrate into microbial cells, which implies lower concentrations of nano-silver would be sufficient for microbial control.
The present study emphasizes the use of plant material for the synthesis of AgNPs with antifungal effect. It is clear that green nanoparticles have a great potential even at very low concentrations in the management of post-harvest anthracnose and future research may have to focus on the consumer 
acceptability of nano treated fruits in the market.

\section{References}

Aguilar-Méndez, M. A., Martín-Martinez, E. S., Ortega-Arroyo, L., Cobián-Portillo, G. and Sánchez-Espíndola, E, 2011. Synthesis and characterization of silver nanoparticles: effect on phytopathogen Colletotrichum gloeosporioides. J. Nanopart. Res. 13: 25- 32.

Banik, S., and Sharma, P., 2011. Plant pathology in the era of nanotechnology. Indian Phytopath. 64 (2): 120-127.

Bobbarala1, V., Katikala, P. K., Naidu K. C., and Penumaj, S. 2009. Antifungal activity of selected plant extracts against phytopathogenic fungi Aspergillus niger f2723. Indian J. Sci. Technol. 2: 87-90.

Chowdappa, P., Gowda, S., Chethana, C. S., and Madhura, S, 2014. Antifungal activity of chitosan-silver nanoparticle composite against Colletotrichum gloeosporoides associated with mango anthracnose. African J. Microbiol. Res. 1803-1812.
Elumalai, E. K., and Vinothkumar, P, 2013. Role of silver nanoparticle against plant pathogens. Nano Biomed. Eng. 5(2), 90-93.

Gomez, K. A., and Gomez, A. A, 1984. Statistical Procedure for Agricultural Research. Wiley, New York, p. 78-85.

Korsten, L., 2006. Advances in control of postharvest diseases in tropical fresh produce. Int. J. Postharvest Technol. Innov. 1: 48-61.

Lamsal, K., Kim, S. K., Jung, J. H., Kim, Y, Kim, K., and Lee, Y, 2011. Application of silver nanoparticles for the control of Colletotrichum species in vitro and pepper anthracnose disease in field. Mycobiol, 39(3): 194-199.

Samuel, U., and Guggenbichler, J. P, 2004. Prevention of catheter related infections: the potential of a new Nanosilver impregnated catheter. Int. J. Antimicrob. Agents, 23(1): 75-78.

Vincent, J. M., 1947. Distortion of fungal hyphae in presence of certain inhibitors. Nature, 159: 239-241.

Wheeler, B. E. J., 1969. An Introduction to Plant Diseases. John Willey and Sons Ltd., London, p. 301.

\section{How to cite this article:}

Divya Jagana, Yashoda R. Hegde and Rajasekhar Lella. 2017. Green Nanoparticles - A Novel Approach for the Management of Banana Anthracnose Caused by Colletotrichum musae. Int.J.Curr.Microbiol.App.Sci. 6(10): 1749-1756. doi: https://doi.org/10.20546/ijcmas.2017.610.211 